\title{
A rapid, non-invasive procedure for quantitative assessment of drought survival using chlorophyll fluorescence Nick S Woo ${ }^{1}$, Murray R Badger ${ }^{2}$ and Barry J Pogson*1
}

\author{
Address: ${ }^{1}$ Australian Research Council Centre of Excellence in Plant Energy Biology, School of Biochemistry and Molecular Biology, the Australian \\ National University, Canberra, ACT 0200, Australia and 2Australian Research Council Centre of Excellence in Plant Energy Biology, Research \\ School of Biological Sciences, the Australian National University, Canberra, ACT 0200, Australia \\ Email: Nick S Woo - nick.woo@anu.edu.au; Murray R Badger - murray.badger@anu.edu.au; Barry J Pogson* - barry.pogson@anu.edu.au \\ * Corresponding author
}

Published: II November 2008

Plant Methods 2008, 4:27 doi:10.1 186/1746-48|I-4-27

This article is available from: http://www.plantmethods.com/content/4/I/27

(C) 2008 Woo et al; licensee BioMed Central Ltd.

This is an Open Access article distributed under the terms of the Creative Commons Attribution License (http://creativecommons.org/licenses/by/2.0), which permits unrestricted use, distribution, and reproduction in any medium, provided the original work is properly cited.
Received: 28 July 2008

Accepted: II November 2008

\begin{abstract}
Background: Analysis of survival is commonly used as a means of comparing the performance of plant lines under drought. However, the assessment of plant water status during such studies typically involves detachment to estimate water shock, imprecise methods of estimation or invasive measurements such as osmotic adjustment that influence or annul further evaluation of a specimen's response to drought.

Results: This article presents a procedure for rapid, inexpensive and non-invasive assessment of the survival of soil-grown plants during drought treatment. The changes in major photosynthetic parameters during increasing water deficit were monitored via chlorophyll fluorescence imaging and the selection of the maximum efficiency of photosystem II $\left(F_{v} / F_{m}\right)$ parameter as the most straightforward and practical means of monitoring survival is described. The veracity of this technique is validated through application to a variety of Arabidopsis thaliana ecotypes and mutant lines with altered tolerance to drought or reduced photosynthetic efficiencies.

Conclusion: The method presented here allows the acquisition of quantitative numerical estimates of Arabidopsis drought survival times that are amenable to statistical analysis. Furthermore, the required measurements can be obtained quickly and non-invasively using inexpensive equipment and with minimal expertise in chlorophyll fluorometry. This technique enables the rapid assessment and comparison of the relative viability of germplasm during drought, and may complement detailed physiological and water relations studies.
\end{abstract}

\section{Background}

With the increasing demands of industrial, municipal and agricultural consumption on dwindling water supplies [1], the development of sustainable farming practices has taken higher priority. For this reason, advancement of the current understanding of plant responses to drought stress and the mechanisms involved has become a major target of research and investment, with the ultimate goal of developing crops with improved water use efficiencies and minimized drought-induced loss of yield $[2,3]$. On a multi-gene scale, analysis of quantitative trait loci allows identification of genetic regions responsible for control of complex responses such as the co-ordination of the whole-plant response to water deficit $[4,5]$. In parallel to this, as our comprehension of the molecular signaling events leading to drought responses has increased, genetic 
engineering techniques now also permit the manipulation of these response mechanisms through targeted overexpression or suppression of specific genes $[3,6]$.

Irrespective of the method used to generate plants with altered drought responses, their performance under drought conditions must be evaluated in order to determine their effectiveness. This introduces a number of experimental decisions, not only with respect to the manner in which water deficit is applied, but also the means used to assess the drought stress response. In regards to the application of water deficit to small model plants such as Arabidopsis thaliana several alternative procedures are in common use, including the detachment of leaves or whole rosettes [7], air-drying of uprooted plants [8], or the transfer of specimens to solute-infused media [9]. Rosette detachment and uprooting are suitable for assessment of a plant's ability to resist rapid water loss using dehydration avoidance mechanisms, such as stomatal closure. In contrast, growth on solute-infused media allows exposure of specimens to a defined level of water deficit over a longer period of time, and thus is a valid means of evaluating adaptive responses [10]. Possibly the most straightforward and relevant application of drought stress is through experiments where water is withheld from soilgrown plants. Soil-drying techniques are generally regarded as the most practical means of approximating field drought conditions for laboratory-based research. However, their use introduces complicating factors such as variation in leaf or soil water loss rates due to differences in plant size and soil composition $[10,11]$ and may necessitate the monitoring and adjustment or control of soil water content $[12,13]$.

In order for soil-drying experiments to yield quantifiable comparisons between genotypes it is crucial that a suitable method of assessment be employed $[11,14]$. Measurements of stomatal conductance $[15,16]$, leaf or soil water potential $[12,17]$ or plant relative water content (RWC) [12] provide meaningful quantitative data and are necessary in a detailed physiological analysis of drought response characteristics. However, determination of leaf water potential or water content involves destructive analyses that may influence future measurements and may not accurately represent the plant as a whole. Physical disturbance to specimens is also typically unavoidable during analyses of transpiration and soil water content. The simplest assessment of viability in response to drought is the capacity of a plant to grow and remain alive under progressively increasing water deficit conditions, and thus it is common practice to utilize such survival assays to compare the drought performance of different plant lines. In such survival experiments, watering is resumed after the majority of specimens appear to have perished, and the percentage of surviving (viable) plants is presented as a measure of the drought tolerance of a line $[7,18-20]$. However, these survival studies rely on qualitative observation of physical symptoms of water deficit stress such as turgor loss, chlorosis, and other qualities that can vary greatly between specimens and are also sensitive to experimental conditions. Critically, the timing of rehydration presents a major problem; for instance, for plants that fail to recover upon rewatering, it is not be possible to determine retrospectively the time at which they perished. Thus, current laboratory-based techniques require either invasive or destructive measurements or are largely subjective and qualitative.

With respect to drought, the negative impact on photosynthesis is well-documented, with carbon assimilation declining progressively with increasing water deficit as a result of both stomatal and metabolic limitations [21-24]. Thus, non-invasive measurement of photosynthesis by chlorophyll $a$ fluorometry $[25,26]$ may potentially provide a means to determine plant viability and performance in response to drought. Measurement of chlorophyll fluorescence by probe-based systems has been utilized for non-invasive analyses of stress-induced perturbations to photosynthesis for several decades $[27,28]$. Indeed, dissection and analysis of the rapid polyphasic chlorophyll $a$ fluorescence transient OJIP [29], a technique applied previously to measure tolerance to light [30] and chilling [31] stresses, was recently employed to assess the response of several barley cultivars to non-lethal drought stress [32]. The recent introduction of chlorophyll fluorescence imaging systems has allowed acquisition of fluorescence data from larger sample areas than probe-based systems $[33,34]$, thereby enabling simultaneous measurement of several specimens and the identification of spatial heterogeneities in photosynthesis across whole leaves or rosettes. Such imaging techniques have also been successfully utilized to examine the impact of numerous environmental stresses [35], including cold [36,37], high light [38] and wounding [34].

In this article, we tested the response of major photosynthetic parameters to increasing water deficit in Arabidopsis with the objective of developing a rapid, reproducible, accurate and non-invasive method for monitoring plant viability in response to prolonged drought. We have developed a procedure that allows a quantitative and precise determination of viability in intact, drought-stressed Arabidopsis plants. The accuracy and general application of this technique has been demonstrated in different wildtype cultivars and in mutant lines that possess differences in drought performance or altered photosynthetic characteristics. 


\section{Results \\ Identification of drought-induced changes in photosynthetic parameters in Arabidopsis wild-type ecotypes}

In order to identify a parameter suitable for monitoring survival in Arabidopsis in response to water deficit, an assessment of common photosynthetic parameters was performed spanning the duration of a prolonged, terminal drought treatment. To verify that any observed trends would be applicable across experiments involving Arabidopsis lines of different ecotypic backgrounds, three commonly-used species of Arabidopsis were examined: Columbia (Col), Landsberg erecta (Ler) and C24.

The maximum efficiency of photosystem II $\left(\mathrm{F}_{\mathrm{v}} / \mathrm{F}_{\mathrm{m}}\right)$ and operating efficiency of photosystem II $\left(\Phi_{\mathrm{PSII}}\right)$ represent the capacity for photon energy absorbed by photosystem II (PSII) to be utilized in photochemistry under dark- and light-adapted conditions respectively [25,39]. As shown in Figures $1 \mathrm{a}$ and $1 \mathrm{~d}, \mathrm{~F}_{\mathrm{v}} / \mathrm{F}_{\mathrm{m}}$ did not vary from levels expected for plants under non-stressed conditions ( 0.800$)$ until late in the course of the treatment, when a slight decline (to 0.700-0.750) was observed. This was followed by a sudden and rapid decline to very low levels (0.100-0.250) over a 2-3-day period, after which very little change was noted. This decrease in $\mathrm{F}_{\mathrm{v}} / \mathrm{F}_{\mathrm{m}}$ affected all rosette leaves and was readily discernible from false-colour images of $\mathrm{F}_{\mathrm{v}} / \mathrm{F}_{\mathrm{m}}$ measurements (Figure 1d). For clarity, Figure 1a shows representative measurements from a single plant of each ecotype; refer to Additional file $1 \mathrm{~b}$ for data from additional biological replicates. $\Phi_{\mathrm{PSII}}$ levels under the growth illumination conditions were likewise stable until the latter stages of drought, at which time a rapid decline was observed (Figure 1b). This decline appeared to precede the decline in $\mathrm{F}_{\mathrm{v}} / \mathrm{F}_{\mathrm{m}}$ by approximately one day; often $\Phi_{\text {PSII }}$ fell to $50 \%$ or less of normal levels before an appreciable change in $\mathrm{F}_{\mathrm{v}} / \mathrm{F}_{\mathrm{m}}$ was noted (Additional file $1 \mathrm{a})$.

Under conditions where absorption of photons exceeds the capacity for their utilization in photochemical processes, excess excitation energy may be dissipated as thermal radiation via xanthophyll-mediated nonphotochemical quenching (NPQ) [40]. NPQ did not show appreciable changes for most of the treatment, with values ranging from approximately $0.8-1.6$ (Figure 1c). During late drought, NPQ levels tended towards the higher end of this range, around 1.6-1.8. This slight increase was followed by a more pronounced decrease to minimal levels, and eventually nil. A number of other photosynthetic parameters were also monitored, including the rate of photosynthetic electron transport (ETR) (Additional file 1c) [39] and non-regulated energy dissipation $\left(\Phi_{\mathrm{NO}}\right)$ (Additional file 1d) [41]. The chlorophyll fluorescence measurements from which the above photo- synthetic parameters have been derived are provided in Additional file 2. All parameters investigated underwent similar changes to those described above, remaining mostly constant before undergoing a sudden, catastrophic decline (or, in the case of $\Phi_{\mathrm{NO}}$, a sudden increase) to critical levels. The rapid decline in photosynthetic parameters occurred concurrently with the appearance of physical symptoms of drought stress, including chlorosis of leaves and loss of turgor (Figure $1 \mathrm{~d}$ ). As $\mathrm{F}_{\mathrm{v}} / \mathrm{F}_{\mathrm{m}}$ is the most readily measurable of these parameters, it was investigated further.

\section{Correlation of the decline in $F_{v} / F_{m}$ with decreased plant water status and viability}

To determine if the rapid decline in $\mathrm{F}_{\mathrm{v}} / \mathrm{F}_{\mathrm{m}}$ during late drought correlates with deterioration in plant water status, the RWC of drought-affected plants exhibiting signs of photosynthetic decline $\left(\mathrm{F}_{\mathrm{v}} / \mathrm{F}_{\mathrm{m}}<0.750\right)$ was determined (Figure 2). Well-watered plants had RWCs of $80-90 \%$ and $\mathrm{F}_{\mathrm{v}} / \mathrm{F}_{\mathrm{m}}$ levels of $\sim 0.800$. Under drought conditions, for RWCs in the range of $20-80 \%, F_{v} / F_{m}$ varied between 0.700-0.750. Plants experiencing critical levels of water deficiency (RWC of 10-20\%) displayed noticeably depressed $F_{v} / F_{m}$ levels, in the range of $0.450-0.750$. The close correlation between the sudden decline in $\mathrm{F}_{\mathrm{v}} / \mathrm{F}_{\mathrm{m}}$ and critical levels of water deficit suggest that the rapid changes in $\mathrm{F}_{\mathrm{v}} / \mathrm{F}_{\mathrm{m}}$ may be a useful indicator of terminal water loss, or loss of viability, at which point plants are unable to recover even if the soil is rehydrated. Association of this loss of viability with the decline of $F_{v} / F_{m}$ beyond a 'threshold' value would provide a convenient, non-invasive means of identifying the time of death of plants subjected to drought.

To determine the threshold for viability, drought-treated Columbia, Landsberg and C24 plants exhibiting $\mathrm{F}_{\mathrm{v}} / \mathrm{F}_{\mathrm{m}}$ measurements in the range $0.100-0.750$ were rehydrated. None of the plants whose $\mathrm{F}_{\mathrm{v}} / \mathrm{F}_{\mathrm{m}}$ measurements were less than the $33 \%$ of the mean $\mathrm{F}_{\mathrm{v}} / \mathrm{F}_{\mathrm{m}}$ of watered control plants showed signs of recovery after 3 days, whereas the large majority $(87 \%)$ of plants with $\mathrm{F}_{\mathrm{v}} / \mathrm{F}_{\mathrm{m}}$ values above this threshold recovered following rehydration (Figure $3 \mathrm{a}, \mathrm{b}$ ). This visible recovery post-rehydration correlated with a gradual recovery in $\mathrm{F}_{\mathrm{v}} / \mathrm{F}_{\mathrm{m}}$ (Figure $3 \mathrm{~b}$ ). For plants that showed no visible signs of recovery, $\mathrm{F}_{\mathrm{v}} / \mathrm{F}_{\mathrm{m}}$ levels remained below 0.300 . Thus, a threshold of $33 \%$ of the mean $F_{v} / F_{m}$ of control plants provides a method to reliably identify non-viable specimens within a severely drought-affected population. The $\mathrm{F}_{\mathrm{v}} / \mathrm{F}_{\mathrm{m}}$ threshold test provides a level of accuracy not possible through visual evaluation alone, as demonstrated in Figure 4 . In this example, $\mathrm{F}_{\mathrm{v}} / \mathrm{F}_{\mathrm{m}}$ measurements were performed on a subset of plants, all of which were classified visually as being dead (Figure 4a, b) despite the presence of viable specimens. Application of the threshold test correctly distinguished between the via- 

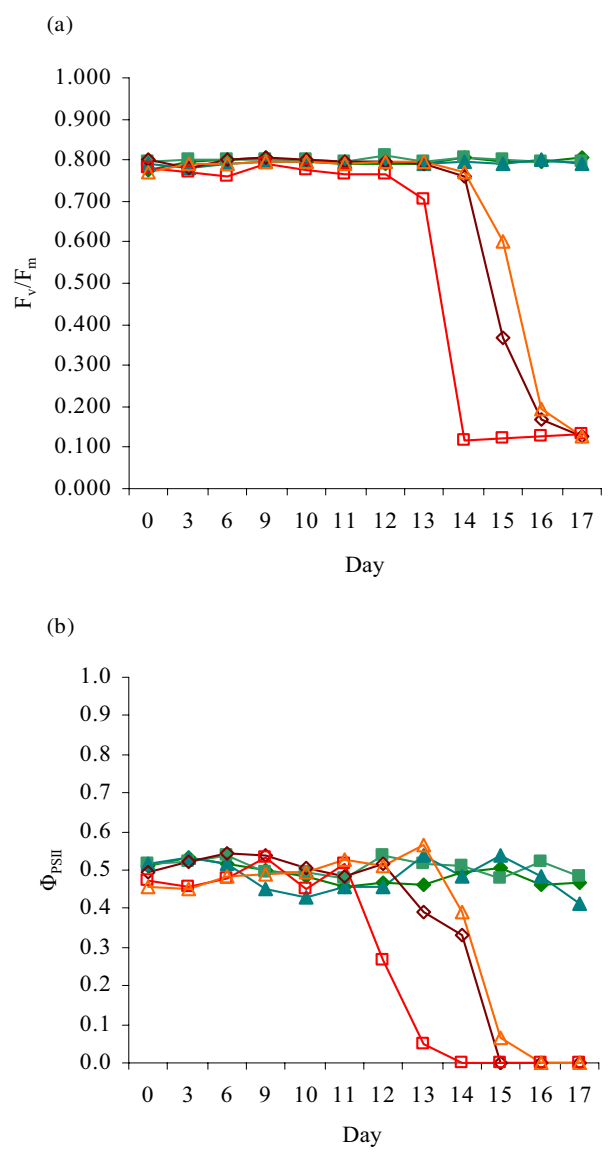

(c)

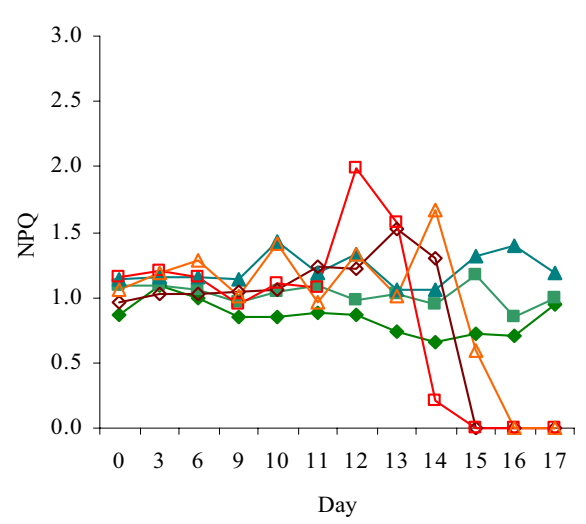

(d)
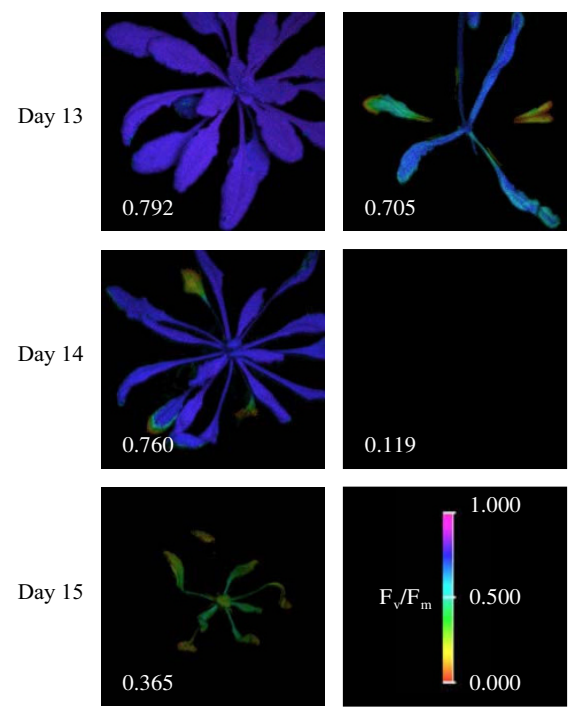

$\mathrm{C} 24$
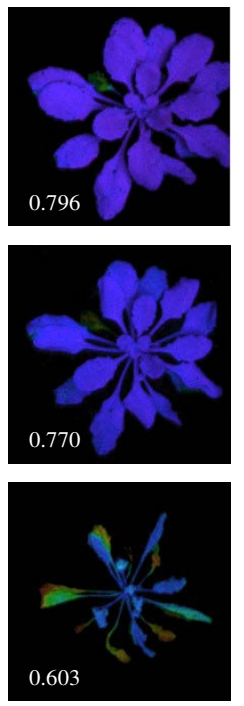

\section{Figure I}

Measurements of (a) $\mathbf{F}_{\mathbf{v}} / \mathbf{F}_{\mathrm{m}}$, (b) $\Phi_{\mathrm{PSII}}$ and (c) NPQ during progression of drought. Measurements are shown for Columbia $(\diamond)$, Landsberg $(\mathrm{h})$ and $\mathrm{C} 24(\Delta)$ plants; filled symbols represent controls, empty symbols represent drought-treated plants. For both control and drought-treated populations, $n=8$ for each line; for clarity, only measurements from one control and one drought specimen of each line are displayed (see Additional file $I b$ for additional $F_{v} / F_{m}$ data). (d) False-colour images of $F_{v} / F_{m}$ measurements obtained from drought-affected specimens during late drought. The average $F_{v} / F_{m}$ measurements of each plant are shown in the lower left corner of the respective images. Note that false-colour images were not generated at $F_{v} / F_{m}$ values of $<\sim 0.125$; for details, refer to Experimental Procedures. The same individual specimens provided all the measurements presented in Figure la-d. 


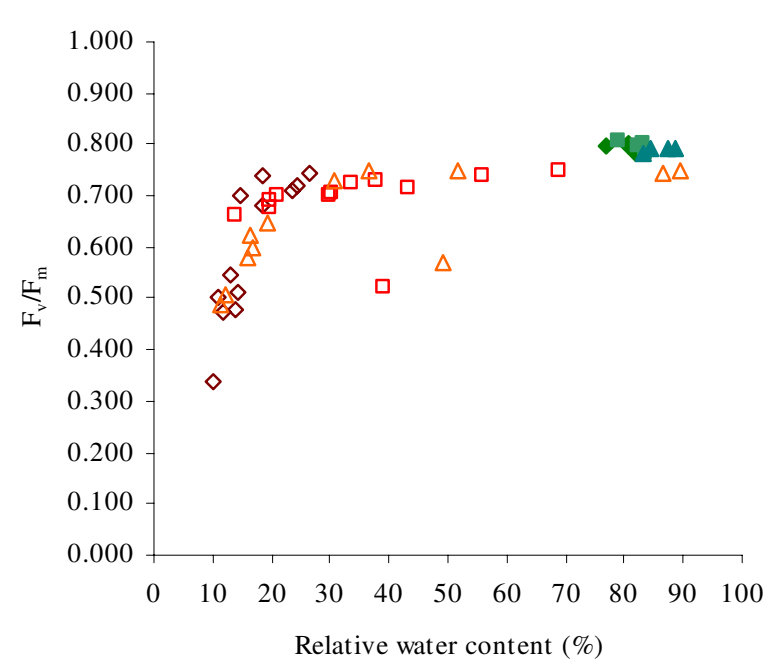

Figure 2

Relationship between $F_{v} / F_{m}$ and plant relative water content. Measurements are shown for Columbia $(\diamond)$, Landsberg (h) and C24 ( $\Delta$ ) plants; filled symbols represent controls, empty symbols represent drought-treated plants. For control populations, $n=4$ for each line; for droughttreated populations, $n=12$ for each line. Data shown are representative of two separate experiments.

ble and non-viable plants, as confirmed through rehydration (Figure 4c).

\section{Case study: Measuring drought survival of water deficit- tolerant Arabidopsis mutants}

To further appraise the precision of the threshold test for viability, it was utilized to perform an assessment of the survival during drought of an established water deficit-tolerant mutant, altered APX2 expression 8 (alx8; At5g63980) [42], and a drought-sensitive mutant, open stomata 1-2 (ost1-2; At4g33950) [43]. Monitoring of $\mathrm{F}_{\mathrm{v}} / \mathrm{F}_{\mathrm{m}}$ levels and application of the threshold test (Figure $5 \mathrm{a}, \mathrm{b}$ ) permitted estimation of plant survival to a specific day (Figure 5c), with loss of viability confirmed via rehydration (data not shown). The experiment demonstrated that al $x 8$ survived an average of 5.0 days longer than Columbia $(p<0.0001)$, while ost1-2 plants lost viability 1.4 days earlier than the Landsberg erecta wild-type parent $(p<0.05)$.

\section{Case study: Measuring drought survival of photosynthetically-impaired Arabidopsis mutants}

The use of the threshold test had now been validated on the common Columbia and Landsberg erecta ecotypes and on mutant plants with altered drought characteristics but comparable photosynthetic efficiencies. To determine whether the $33 \% \mathrm{~F}_{\mathrm{v}} / \mathrm{F}_{\mathrm{m}}$ threshold test remained a valid predictor of viability when applied to Arabidopsis mutants with impaired photosynthetic activities, the drought survival of three variegated lines of Arabidopsis was evaluated. The yellow variegated 1, (var1-1; At5g42270) [44], yellow variegated 2 (var2-2; At2g30950) [45] and altered APX2 expression 13 (alx13) lines exhibit chlorotic sectoring and depressed photosynthetic efficiencies. Depending on the severity of chlorosis, the $\mathrm{F}_{\mathrm{v}} / \mathrm{F}_{\mathrm{m}}$ values of control plants from the three mutant lines varied from $0.650-0.800$, corresponding to threshold values in the range of $0.215-$ 0.264 . The threshold test was applied using the lower threshold values obtained from the mutant controls rather than the threshold of the non-chlorotic Columbia wild-type (Figure 6a-d). In this manner, survival times were estimated as shown in Figure 6e, with all plants failing to recover following rehydration.

\section{Case study: Comparison of a traditional rehydration survival test and the $F_{v} / F_{m}$ threshold test}

The threshold test was next applied to assess the drought survival of transgenic plants altered in the expression of an abiotic stress response transcription factor. The protein encoded by the HL-responsive gene zinc-finger of Arabidopsis 10 (ZAT10; At1g27730) has been shown to function as both a positive and negative regulator of a number of genes involved in the oxidative stress response and is implicated in the activation and suppression of several abiotic stress response pathways, including osmotic, heat and salinity stress [46]. However, overexpression of ZAT10 has been variously reported as either conferring a marked increase in drought resistance [47] or not affecting the drought response at all [46] when assessed using the traditional re-watering survival tests.

Two transgenic lines in which ZAT10 gene expression was suppressed via RNA interference (zat10(i)-1 and zat10(i)3) and two lines in which ZAT10 was constitutively overexpressed under the direction of the cauliflower mosaic virus 35S promoter (35S:ZAT10-6 and 35S:ZAT10-14) were subjected to drought survival analysis via both traditional rehydration methods and our threshold test [48]. As shown in Table 1a, in a traditional rehydration test three zat10(i) plants were shown to survive 20 days' drought treatment whereas all Columbia wild-type and 35S:ZAT10 specimens had perished by this time. The inherent limitations of data obtained from this form of experiment make it difficult to draw substantive conclusions from these results as to whether this difference is significant and accurate. A threshold test survival experiment (Figure 7a, b), in comparison, indicated that length of survival in days was not statistically different for the two RNA interference lines and one of the overexpression lines (Table 1b). Only the 35S:ZAT10-14 line displayed a significantly altered survival in comparison to the wild-type, 
(a)

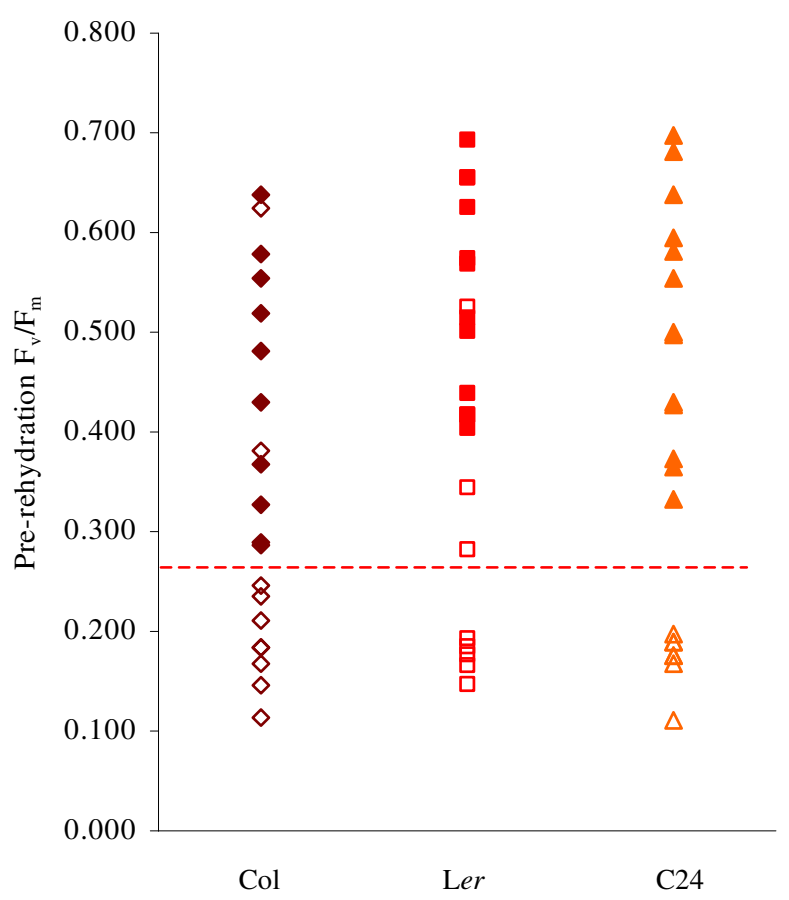

(b)

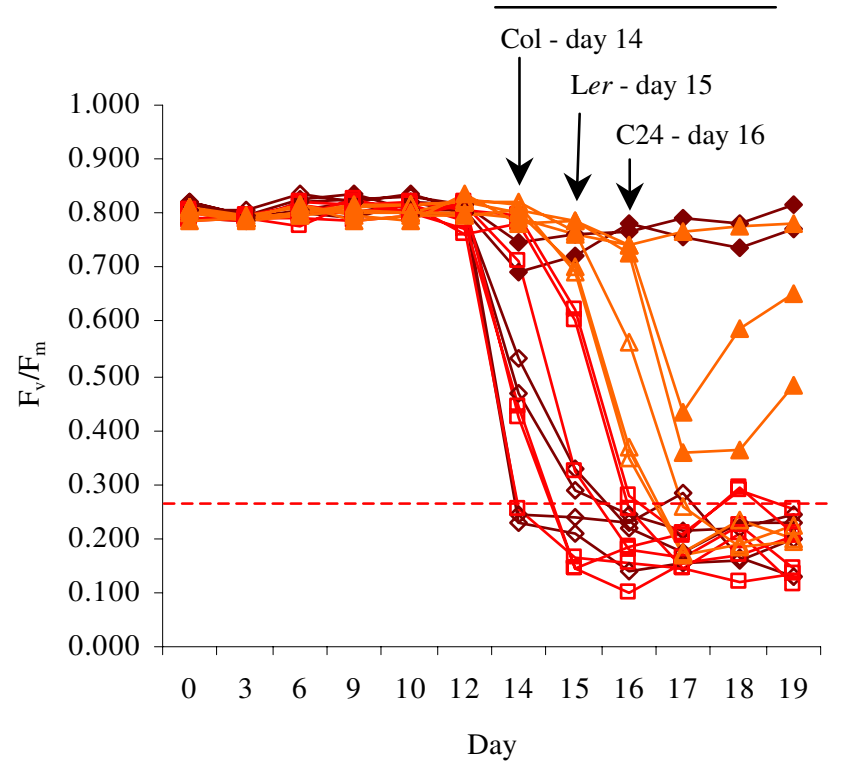

Figure 3

Validation of the $\mathbf{F}_{\mathbf{v}} / \mathbf{F}_{\mathbf{m}}$ threshold test for viability. Drought-affected Columbia $(\diamond)$, Landsberg $(\mathrm{h})$ and $\mathrm{C} 24(\Delta)$ plants were rehydrated after their $F_{v} / F_{m}$ levels were observed to fall below 0.750 . Filled symbols represent plants that recovered within 3 days of rehydration, while empty symbols represent plants that failed to evidence signs of recovery following watering. The $33 \%$ threshold for a typical average control $F_{v} / F_{m}$ of 0.800 is shown as a dotted line. (a) $F_{v} / F_{m}$ measurements of individual specimens immediately prior to rehydration. For each line, $n=20$. (b) Change in $F_{v} / F_{m}$ of drought-treated plants following rehydration. Columbia, Landsberg and C24 plants were rewatered after 14, 15 and 16 days' drought respectively, as indicated by arrows. For each line, $n=6$. The data presented in Figures $3 \mathrm{a}$ and $3 \mathrm{~b}$ were obtained from separate experiments.

a difference which may be considered negligible ( $p$-value $=0.049$ ).

\section{Discussion}

Identification of a photosynthetic parameter suitable for assessment of drought progression

Here we have shown that $\mathrm{F}_{\mathrm{v}} / \mathrm{F}_{\mathrm{m}}$ declines rapidly during late drought and can serve as an indicator of the latter phase of drought and subsequent loss of viability. Although it is possible that the other photosynthetic measurements obtained in this study could be employed as an indicator of viability, the $\mathrm{F}_{\mathrm{v}} / \mathrm{F}_{\mathrm{m}}$ parameter is recommended for several reasons. First, as shown in Figure 1a, $\mathrm{F}_{\mathrm{v}} / \mathrm{F}_{\mathrm{m}}$ values are typically very consistent between lines and individual plants; as such, any small decline is easily noticeable and signifies clearly that loss of viability is imminent. The consistency of the $\mathrm{F}_{\mathrm{v}} / \mathrm{F}_{\mathrm{m}}$ parameter also increases the ease with which a threshold level can be defined. More importantly, unlike light-dependent parameters such as $\Phi_{\mathrm{PSII}}$ and NPQ, $\mathrm{F}_{\mathrm{v}} / \mathrm{F}_{\mathrm{m}}$ is obtained from specimens in the dark-adapted state, negating the need for an extended period of illumination prior to measurement. Thus, as measurement of $\mathrm{F}_{\mathrm{v}} / \mathrm{F}_{\mathrm{m}}$ can be completed using a single saturating pulse, rapid screening of a large number of plants may be achieved.

\section{Quantification of viability using chlorophyll fluorescence measurements}

To employ the decline in $\mathrm{F}_{\mathrm{v}} / \mathrm{F}_{\mathrm{m}}$ as a means of determining viability during drought, it was necessary to identify a threshold $\mathrm{F}_{\mathrm{v}} / \mathrm{F}_{\mathrm{m}}$ level that would reflect a point at which recovery was no longer possible. As it is of course impossible to define an exact threshold level beyond which viability is lost, we identified a conservative threshold of 33\% of control specimen measurements and showed that, in practice, decline of $\mathrm{F}_{\mathrm{v}} / \mathrm{F}_{\mathrm{m}}$ below this level no plants were viable upon re-watering (Figure 3; Figure 4; Figure 5a, b; 
(a)

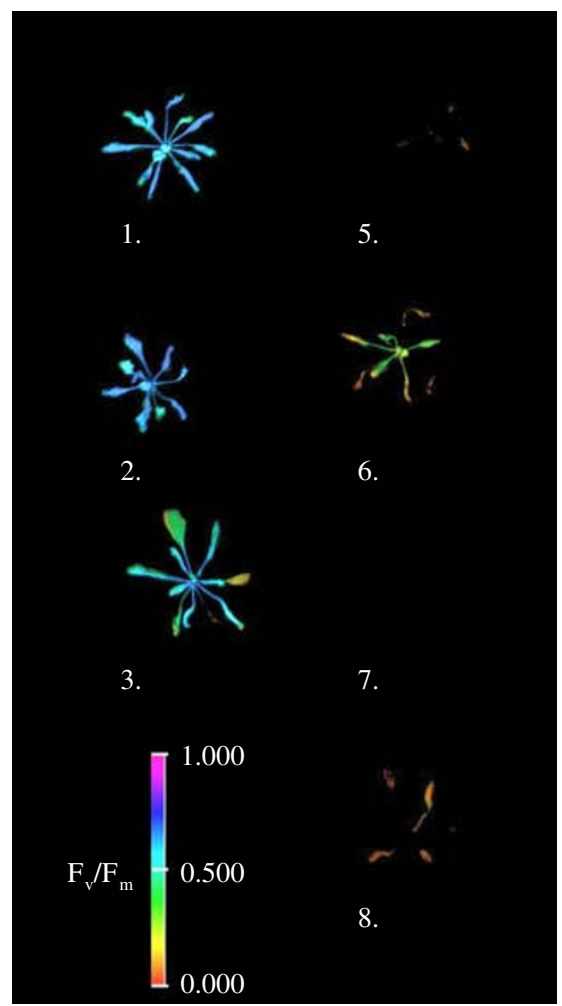

(b)

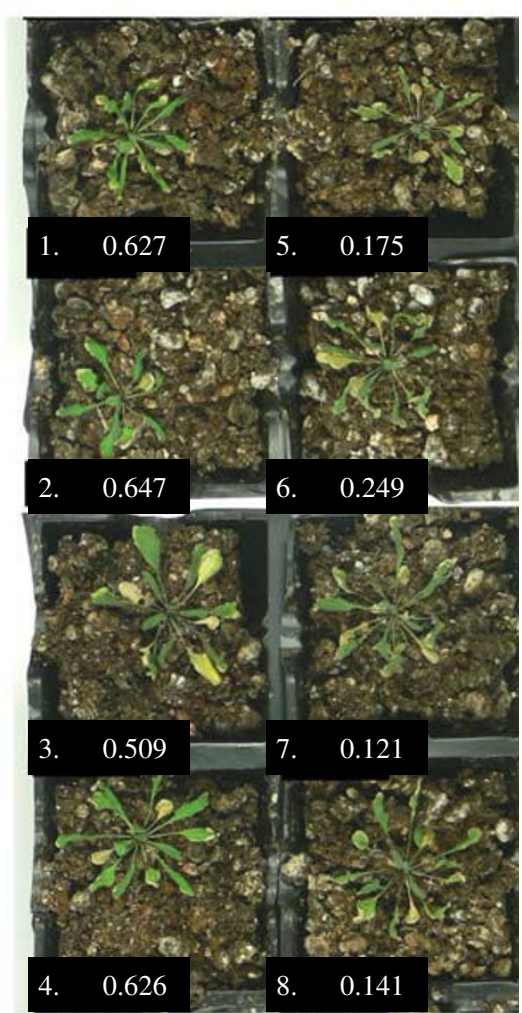

viable non-viable (c)

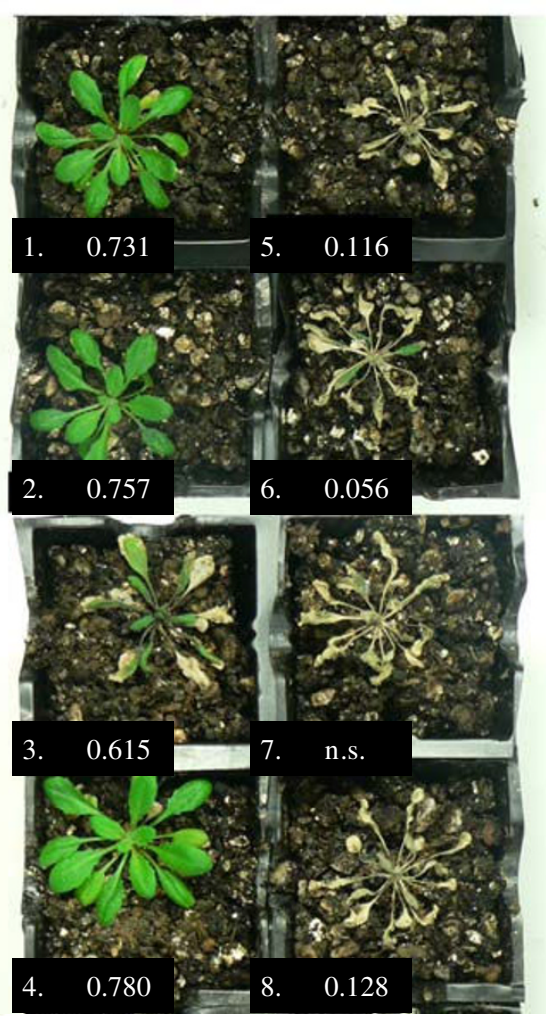

3 days post-rehydration

\section{Figure 4}

Visual estimation of drought survival. (a) False-colour representations of $F_{v} / F_{m}$ measurements of Columbia plants following 15 days' drought treatment. The individual specimens were labeled I through 8 , as indicated by the number below each plant. Note that false-colour images were not generated at $F_{v} / F_{m}$ values of $<\sim 0.125$; for details, refer to Experimental Procedures. The image of plant \#4 has been omitted for provision of the false-colour scale, however its $F_{v} / F_{m}$ measurements were comparable to those of plant \#I. (b) Photograph of the plants shown in (a). $F_{v} / F_{m}$ measurements obtained from each plant are shown in the lower left corner of each punnet. The average $F_{v} / F_{m}$ of control plants (not shown) was 0.800 , providing a threshold $F_{v} / F_{m}$ of 0.264 . The 4 plants in the left column were classified as viable by application of the threshold test $\left(F_{v} / F_{m}>0.264\right)$, while the 4 plants in the right column were classified as non-viable $\left(F_{v} / F_{m}<0.264\right)$. (c) Photograph of the same 8 plants after watering was resumed for 3 days; n.s. $=$ no signal detected.

Figure 6a-d; Figure 7).

To validate the efficacy of the threshold test, the technique was employed to assess the drought performance of the alx 8 and ost1-2 mutant lines previously identified as drought-resistant and drought-sensitive, respectively $[42,43]$. Using this method it was possible to monitor the viability of drought-affected plants and evaluate the survival times of individual plants in a precise and quantifiable manner (Figure 5). The robustness of the threshold test was further confirmed through its application in a drought survival analysis of three variegated lines of Arabidopsis. The variegated lines var1-1, var2-2 and alx13 are sensitive to photoinhibitory damage and consequently have impaired photosynthetic efficiencies. This impairment is manifest in reduced $F_{v} / F_{m}$ levels in each of the three mutant lines, which in turn necessitated the application of their respective control $\mathrm{F}_{\mathrm{v}} / \mathrm{F}_{\mathrm{m}}$ levels to calculate the $33 \%$ thresholds. The threshold test successfully ascertained loss of viability in specimens of all three mutants, 
(a) Columbia versus alx8

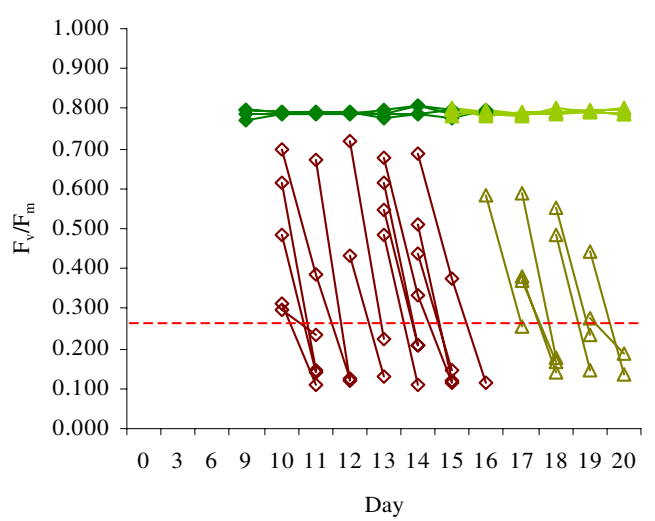

(b) Landsberg versus ost $1-2$
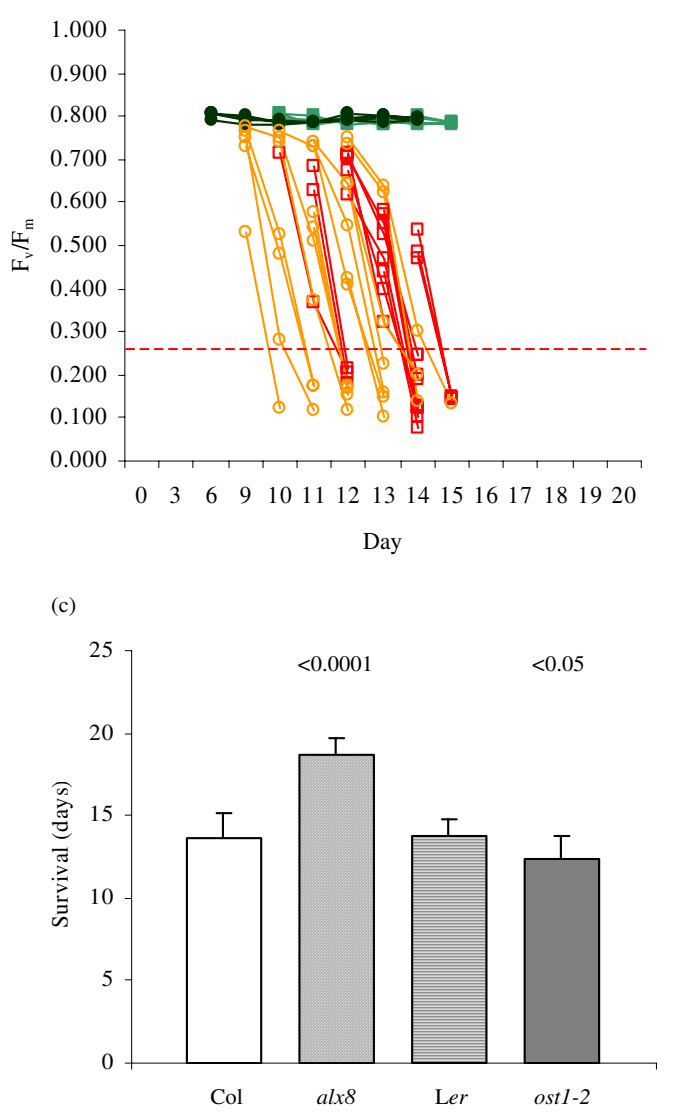

\section{Figure 5}

Drought survival analysis of alx 8 and ost $I-2$ plants. (a, b) Application of the threshold test. The $F_{v} / F_{m}$ measurements of individual (a) Columbia $(\diamond)$ and alx8 $(\Delta)$, and (b) Landsberg $(\mathrm{h})$ and ost $/-2(\bigcirc)$ specimens are shown. Filled symbols represent controls; empty symbols represent plants that failed to evidence signs of recovery within 3 days of rehydration. The $33 \%$ threshold for a typical average control $F_{v} / F_{m}$ of 0.800 is shown as a dotted line. For control populations, $n=4$ for each line; for drought-treated populations, $n=15$ for Columbia, Landsberg and ost $I-2$, and $n=8$ for alx8. (c) Comparison of drought survival times of $a l \times 8$, ost $I-2$ and wild-type plants. Error bars indicate standard deviation. Pairwise $t$-tests were performed for the mutant lines against survival times of their corresponding wild-type (Columbia for alx8, Landsberg for ost I-2), yielding $p$-values as shown. 


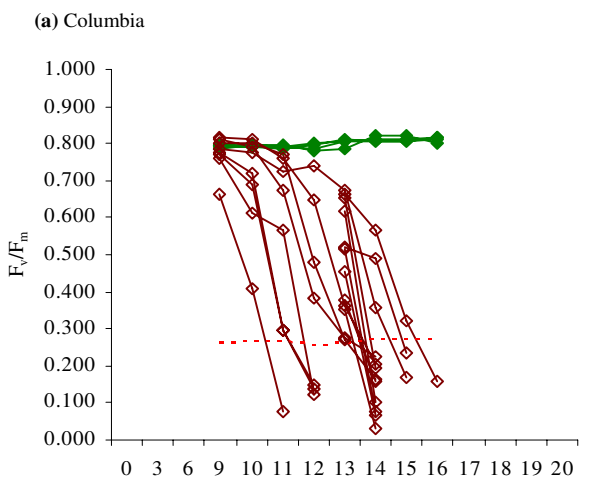

Day

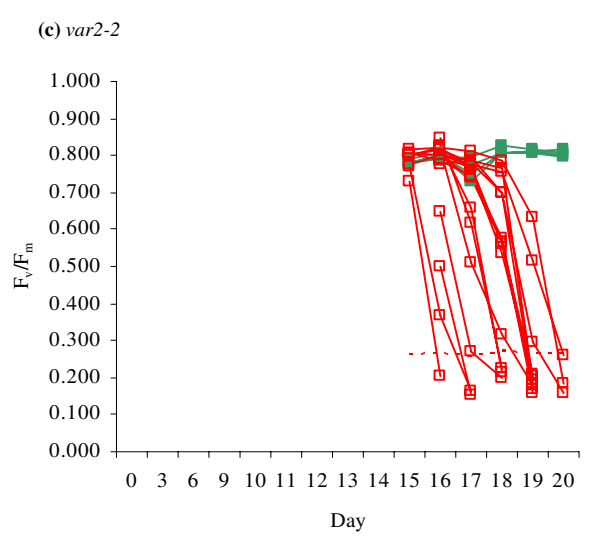

(e)

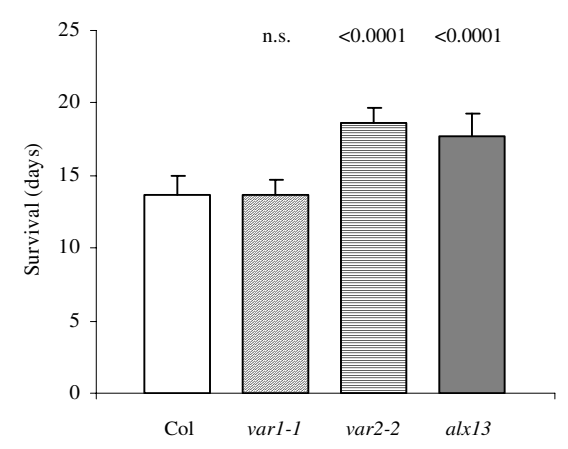

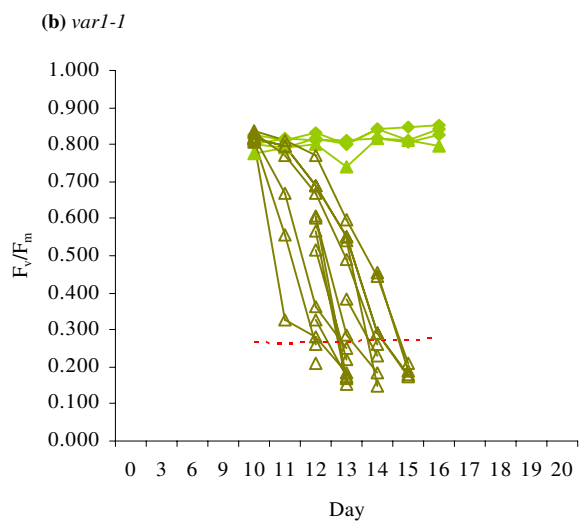

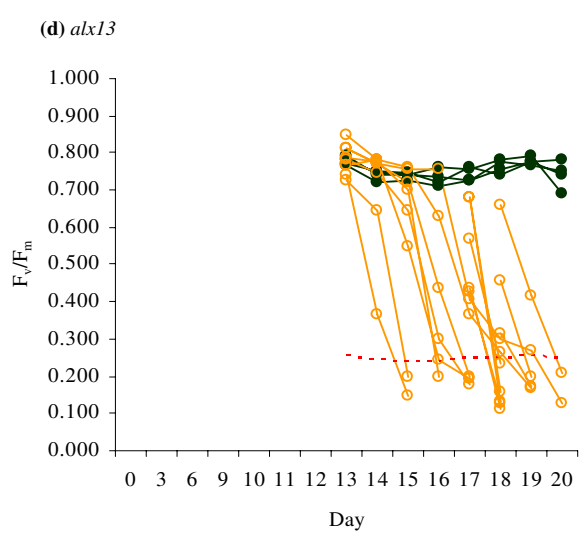

\section{Figure 6}

Drought survival analysis of variegated lines of Arabidopsis. (a-d) Application of the threshold test. The $F_{v} / F_{m}$ measurements of individual (a) Columbia $(\diamond)$, (b) varl-I ( $\Delta$ ), (c) var2-2 (h) and (d) alx I3 $(\bigcirc)$ specimens immediately prior to rehydration are shown. Filled symbols represent controls; empty symbols represent plants that failed to evidence signs of recovery within 3 days of rehydration. The $33 \%$ threshold for each line is shown as a dotted line. For control populations, $n=7$ for each line; for drought-treated populations, $n=16$ for each line. For clarity, only measurements from 4 control plants are shown. (e) Comparison of drought survival times of variegated lines. Error bars indicate standard deviation. Pairwise $t$-tests were performed against survival times of wild-type Columbia plants, yielding $p$-values as shown; n.s. $=$ not significant. Data shown are the combined results of two separate experiments. 
(a) Columbia, zat10(i)-1 and zat10(i)-3

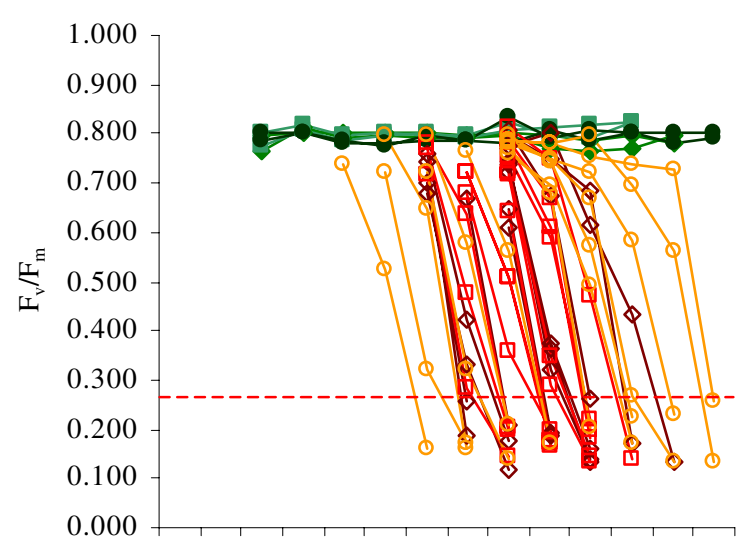

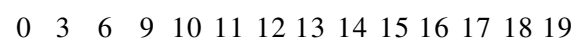

Day

(b) 35S:ZAT10-6 and 35S:ZAT10-14

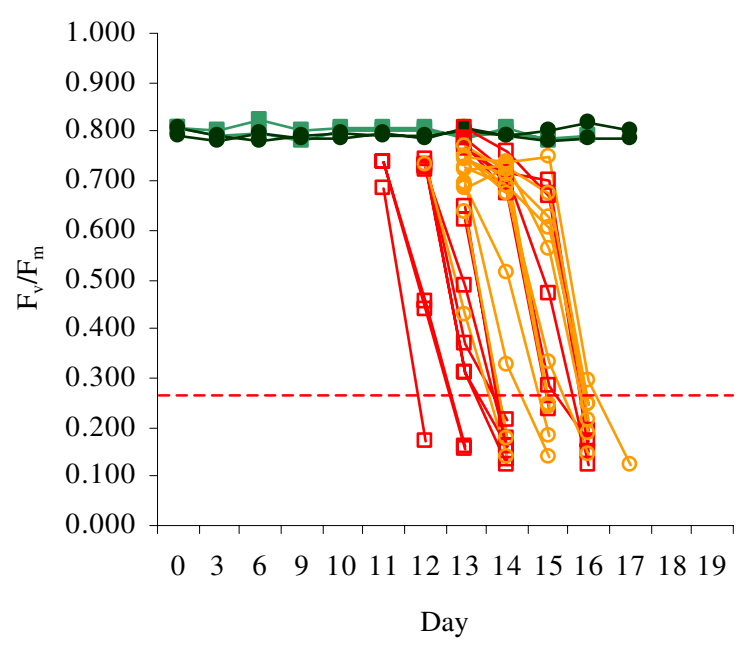

Figure 7

Drought survival analysis of ZATIO transgenic plants. Application of the threshold test. The $F_{v} / F_{m}$ measurements of individual (a) Columbia $(\diamond)$, zat I0(i)-I (h) and zat I0(i)-3 (O), and (b) 35S:ZATI 0-6 (h) and 35S:ZATI0-I 4 (O) specimens are shown. Filled symbols represent controls; empty symbols represent plants that failed to evidence signs of recovery within 3 days of rehydration. The $33 \%$ threshold for a typical average control $F_{v} / F_{m}$ of 0.800 is shown as a dotted line. For control populations, $n=2$ for each line; for drought-treated populations, $n=13$ for each line.

demonstrating its utility even in situations where photodamage and differing photosynthetic capacities are present (Figure 6). Intriguingly, the test also indicated differences in drought survival between the mutants and wild-type, a discovery that is under further investigation.
As a demonstration of the advantages of the threshold test, the drought survival of ZAT10 transgenic lines were evaluated using both the threshold test technique and the traditional rehydration method. The limitations of the traditional rehydration test (Table $1 \mathrm{a}$ ) are apparent: although three zat10(i) specimens remained viable at the end of the experiment, the extent of this increased survival is cannot be established as there is no indication of the time at which wild-type plants became inviable. Indeed, as this test does not yield survival data for individual specimens it is not possible to determine whether the surviving plants are outliers among their populations, nor can the variability in survival times within each population be estimated. It cannot be ascertained at all whether 35S:ZAT10 plants exhibit altered drought survival compared to the wild-type.

The threshold test, in contrast, provides a far more informative assessment of drought survival. From the data presented in Table 1b and Figure 7 it is immediately evident that the survival times of all of the lines in the threshold test experiment were very similar, with average survival times indicating that the loss of viability of all lines occurred within a 1-day period. Statistical assessment of the survival times of the transgenic lines indicated that 35S:ZAT10-14 plants may remain viable during drought for slightly longer than the wild-type, but also show that any increased viability is at most marginally significant. Note that the results shown in Table 1 are for the purposes of demonstrating differences in the interpretation of traditional and threshold survival test methods and do not represent a comprehensive analysis of the effect of altered ZAT1O expression on the drought response; such an investigation would require monitoring of additional parameters such as the extent of ZAT10 overexpression/suppression.

\section{Applications and suggestions for using the threshold test for measuring viability}

The threshold test offers a reliable, rapid and quantitative alternative to conventional studies of drought survival in Arabidopsis. As only minimal technical expertise and a basic understanding of chlorophyll fluorometry are required to obtain the necessary measurements, the threshold test may appeal to a broad spectrum of plant science laboratories. Further, this procedure does not require the use of expensive or esoteric equipment. Although the results presented in this analysis were produced using an IMAGING-PAM system (Walz; Effeltrich, Germany) and have also been validated using a Chlorophyll Fluorescence Imager (Technologica; Colchester, UK) (data not shown), a number of less costly devices are available. For example, the FluorPen (Photon Systems Instruments; Brno, Czech Republic) and Pocket PEA Chlorophyll Fluorimeter (Hansatech; Norfolk, UK) offer convenient means of monitoring $\mathrm{F}_{\mathrm{v}} / \mathrm{F}_{\mathrm{m}}$ levels both in the 
Table I: Drought survival analyses of ZATIO transgenic plants using traditional and threshold test methods.

\begin{tabular}{|c|c|c|c|c|c|c|}
\hline & Line & Col & zat IO(i)-I & zat l0(i)-3 & 35S:ZATI 0-6 & 35S:ZATI0-I4 \\
\hline (a) & \# of viable plants post-rehydration & $0 / 7$ & $2 / 7$ & $\mathrm{I} / 7$ & $0 / 7$ & $0 / 7$ \\
\hline (b) & $\begin{array}{c}\text { Survival time (days) } \pm \text { s.d. } \\
\text { t-test }\end{array}$ & $\begin{array}{c}15.2 \pm 1.5 \\
-\end{array}$ & $\begin{array}{l}15.3 \pm 0.9 \\
\text { n.s. }\end{array}$ & $\begin{array}{l}15.8 \pm 2.5 \\
\text { n.s. }\end{array}$ & $\begin{array}{l}15.5 \pm 1.2 \\
\text { n.s. }\end{array}$ & $\begin{array}{l}16.2 \pm 1.1 \\
\quad \sim 0.05\end{array}$ \\
\hline
\end{tabular}

(a) Traditional rehydration survival test results. Plants were subjected to drought treatment for 20 days, after which watering was resumed; values indicate the number of plants that recovered within 3 days of rehydration. For each line, $n=7$. (b) Threshold survival test results. For control populations, $n=2$ for each line; for drought-treated populations, $n=13$ for each line. s.d. = standard deviation. Pairwise $t$-tests were performed against survival times of wild-type Columbia plants, yielding $p$-values as shown; n.s. = not significant.

laboratory and in the field at low cost. Instruments such as these are also amenable for determination of the OJIP fluorescence transient [29], and therefore offer the potential for assessment of plant performance during early and moderate phases of drought treatment [32] in addition to drought survivability. However, when employing a fluorescence probe it may be necessary to acquire several measurements in order to account for heterogeneities in photosynthetic efficiencies across the leaf surface of plants, particularly severely drought-stressed specimens.

While beyond the scope of this report, it is easily conceivable that the threshold test may be successfully applied to monitor the survival of plants under different forms of abiotic stress, particularly those that cause progressive deterioration of photosynthetic efficiencies. Prolonged cold or light stress, for example, can induce accumulative photoinhibitory damage to the photosynthetic machinery to the point at which a specimen is no longer able to sustain vital functions $[49,50]$. Likewise, it is quite likely that the threshold test could be adapted for use with other plant species. We have targeted Arabidopsis as this rapid test could be applied to mutant and genotype screens in advance of detailed analyses of water relations.

\section{A discussion of the drought-induced changes in chlorophyll fluorescence parameters in Arabidopsis}

While an investigation of the physiological and photochemical bases of the observed drought-induced changes in chlorophyll fluorescence was not an objective of this report, they will be discussed briefly in this section. Measurements of the maximum and operating efficiencies of PSII, as represented by $\mathrm{F}_{\mathrm{v}} / \mathrm{F}_{\mathrm{m}}$ and $\Phi_{\mathrm{PSII}}$ respectively, indicated that there was no significant perturbation of PSII photochemistry or electron transport capacity within the photosystems despite the initial significant decreases in RWC (Figure 1a, b; Figure 2). Indeed, only when plant water reserves declined to critical levels $(<20 \%$ RWC) were $\mathrm{F}_{\mathrm{v}} / \mathrm{F}_{\mathrm{m}}$ measurements consistently reduced. These results are similar to observations in sunflower, where $\mathrm{F}_{\mathrm{v}} / \mathrm{F}_{\mathrm{m}}$ was unchanged across a comparable range of water deficit stress [22], in pea, where only a slight decrease was noted despite RWC as low as $20 \%$ [51], and in triticale, where extended drought failed to alter $\mathrm{F}_{\mathrm{v}} / \mathrm{F}_{\mathrm{m}}$ significantly [52]. Thus, although drought is known to cause gradual inhibition of assimilatory photochemistry through both stomatal [24] and metabolic [22] restriction of $\mathrm{CO}_{2}$ availability, photosynthetic electron transport may be maintained throughout the course of drought treatment through dissipation of excess excitation energy by alternative electron sinks $[40,53]$.

During prolonged water deficit, severe reduction of cellular water content results in enhanced leaf senescence, as reflected by elevated levels of reactive oxygen intermediates and chlorophyll degradation $[54,55]$. Thus, it is possible that the rapid decline in photosynthetic parameters observed during the latter stages of drought is attributable to senescence-induced chlorosis and disruption of the photosynthetic apparatus. The rapid photosynthetic decline during late drought may therefore be a consequence of the damage to PSII reaction centres or associated chlorophylls [56], although it has previously been suggested that drought-induced suppression of photosynthetic efficiencies may be due to the deterioration of an electron carrier at the donor side of PSII, rather than destruction of the PSII reaction centre or of chlorophyll molecules [57]. Chlorophyll fluorescence measurements may also be influenced by non-photosynthetic alterations in leaf physiology associated with prolonged drought, such as changes in leaf angle due to loss of turgor. Irrespective of the mechanisms responsible for the observed photosynthetic decline, though, the rapid change in the $\mathrm{F}_{\mathrm{v}} / \mathrm{F}_{\mathrm{m}}$ parameter may nonetheless be employed via the threshold test as a means of estimating drought survival.

\section{Conclusion}

In this report, we describe a method of determining the survival of drought-treated Arabidopsis utilizing measurements of the $F_{v} / F_{m}$ chlorophyll fluorescence parameter. Although photosynthetic parameters remained mostly unchanged during the first phase of drought treatment, a sudden deterioration in photosynthesis was observed to occur just prior to the terminal stages of drought and the loss of plant viability. By correlating the decline in the $\mathrm{F}_{\mathrm{v}} /$ $\mathrm{F}_{\mathrm{m}}$ parameter to this loss of viability, a procedure was 
developed to allow the monitoring of survival under water deficit conditions, namely defining a threshold of $33 \%$ of well-watered $\mathrm{F}_{\mathrm{v}} / \mathrm{F}_{\mathrm{m}}$ values. The versatility of this technique was demonstrated through comparison of the drought performance of a number of Arabidopsis cultivars and to a variety of mutants with altered drought tolerance or photosynthetic capacity. As a rapid, non-invasive and inexpensive procedure, the threshold test for survival holds much value in screening for altered responses to drought in Arabidopsis germplasm. This procedure may complement existing methods of evaluating drought performance utilizing chlorophyll fluorescence [32], and increase the number of tools available for assessment of this and potentially other plant stresses.

\section{Methods}

Plant growth conditions and drought treatments

All Arabidopsis thaliana plants were cultivated under $100 \pm$ $10 \mu \mathrm{mol}$ photons $\mathrm{m}^{-2} \mathrm{~s}^{-1}$, 8-hour photoperiod, $23^{\circ} \mathrm{C} /$ $22{ }^{\circ} \mathrm{C}$ day/night temperatures, $50 \% / 70 \%$ day/night humidity. Seed were sown on a moistened, looselypacked 3:1 mixture of soil:vermiculite, then vernalized at $4^{\circ} \mathrm{C}$ in darkness for 72 hours before transfer to growth conditions. Prior to initiating drought treatment plants were watered every second day, with every third watering supplemented with $0.5 \times$ Hoagland's Fertilizer [58]. After 7 days' growth, seedlings were thinned to leave one plant per punnet. Drought treatments were initiated when plants were 28 days' old, at which time all specimens were at $~ 12$-leaf stage, with the exception of assays involving variegated mutant lines and ZAT10 transgenic lines. In the experiments involving variegated mutants, in order to account for differences in developmental rates, Columbia populations began treatment at 30 days of age, alx13 at 33 days, and var1-1 and var2-2 at 37-40 days, at which times all plants were at $~ 14$-leaf stage. For the traditional rehydration survival analysis of ZAT10 transgenic lines, drought treatment was initiated at 28 days' of age; after 20 days rehydration was performed as described below. For the threshold survival test of ZAT10 lines, drought treatment was initiated at 42 days' of age.

For drought treatments, all plants were first provided with a sufficiency of water. Punnets containing plants to be subjected to drought were then removed to water-free trays with spaces between specimens to allow air flow, and further watering withheld; all other environmental conditions were maintained as described above. Control plants remained under watered conditions for the duration of the experiment. Where rehydration was necessary, punnets were returned to watered trays for 72 hours. Plants that failed to exhibit any physical signs of recovery within this time were deemed to have lost viability.

\section{Measurement of photosynthetic parameters}

Chlorophyll fluorescence measurements were performed using an IMAGING-PAM chlorophyll fluorometer and ImagingWin software application (Walz; Effeltrich, Germany). For assessment of dark- and light-adapted parameters, a dark-light induction curve was performed. Darkadapted plants were subjected to an initial saturating pulse of $>1800 \mu \mathrm{mol}$ photons $\mathrm{m}^{-2} \mathrm{~s}^{-1}$, followed by a $40 "$ delay in darkness and subsequently 10' of actinic illumination with saturating flashes at 20" intervals. An actinic irradiance of $100 \pm 10 \mu \mathrm{mol}$ photons $\mathrm{m}^{-2} \mathrm{~s}^{-1}$ was used to simulate growth conditions. The following parameters were derived from the final measurements obtained after the 10 ' light adaptation: $\Phi_{\mathrm{PSII}} \Phi_{\mathrm{NO}^{\prime}}$ NPQ and ETR. $\mathrm{F}_{\mathrm{v}} / \mathrm{F}_{\mathrm{m}}$ values were taken as the measurement of $\Phi_{\mathrm{PSII}}$ at time zero. The four primary fluorescence signals $-\mathrm{F}_{\mathrm{o}^{\prime}}, \mathrm{F}_{\mathrm{m}^{\prime}} \mathrm{F}_{\mathrm{s}}{ }^{\prime}$ and $\mathrm{F}_{\mathrm{m}}{ }^{\prime}$ - from which the above photosynthetic parameters were derived are shown in Additional file 2. For background information regarding photosynthetic parameters and theoretical aspects of chlorophyll fluorescence, refer to $[25,26,39,41]$. To account for variations in photosynthetic parameters across the surface of individual plants, the data presented are the average values obtained across individual rosettes. Note that, where false-colour images of the $\mathrm{F}_{\mathrm{v}} / \mathrm{F}_{\mathrm{m}}$ parameter are shown, the ImagingWin software eliminates pixels in areas where $\mathrm{F}_{\mathrm{m}}<0.040$ in order to reduce background noise. For this reason, $F_{v} / F_{m}$ images of certain severely drought-affected plants were unobtainable; in these instances the average $\mathrm{F}_{\mathrm{v}} / \mathrm{F}_{\mathrm{m}}$ measurements alone are presented.

For experiments requiring only determination of $\mathrm{F}_{\mathrm{v}} / \mathrm{F}_{\mathrm{m}}$, measurements were obtained from application of a single saturating pulse to dark-adapted plants. All photosynthetic measurements were performed prior to dawn, after 12-16 hours' dark adaptation. For accurate measurement of $F_{v} / F_{m}$ a dark adaptation of $>15$ minutes is typically sufficient.

\section{Determination of relative water content}

For measurements of rosette RWC, the entire aerial parts of the plant were harvested using a single incision to the base of the stem, and the fresh weight (FW) of the rosette determined. The rosette was then floated on distilled water in darkness at $4^{\circ} \mathrm{C}$ for 24 hours before determination of turgid weight (TW). The rosette was then placed in a paper envelope and dried at $65^{\circ} \mathrm{C}$ for 24 hours, and the desiccated sample weighed once more to determine dry weight (DW). RWC was calculated from these measurements as follows:

$\mathrm{RWC}=((\mathrm{FW}-\mathrm{DW}) /(\mathrm{TW}-\mathrm{DW})) \times 100 \%$

\section{Competing interests}

The authors declare that they have no competing interests. 


\section{Authors' contributions}

NW conceived of the described procedure, performed all photosynthetic measurements and drought studies and prepared the manuscript. All authors participated in experimental design and data analysis. All authors read and approved the final manuscript.

\section{Additional material}

\section{Additional File 1}

Additional measurements of photosynthetic parameters during progression of drought.

Click here for file

[http://www.biomedcentral.com/content/supplementary/17464811-4-27-S1.ppt]

\section{Additional File 2}

Raw chlorophyll fluorescence parameters $\left(F_{o^{\prime}}, F_{m^{\prime}}, F_{s}{ }^{\prime}\right.$ and $\left.F_{m}{ }^{\prime}\right)$ during progression of drought.

Click here for file

[http://www.biomedcentral.com/content/supplementary/17464811-4-27-S2.ppt]

\section{Acknowledgements}

We acknowledge the support of the Australian Research Council Centre of Excellence in Plant Energy Biology (CE056 I 495). We also thank Susanne von Caemmerer and Simon Dwyer for assistance with photosynthetic measurements, Pip Wilson and Gonzalo Estavillo for assistance with the al $x 8$ and ost $I-2$ lines, and Peter Crisp and Tim Sloan-Gardner for assistance in the preparation of the manuscript.

\section{References}

I. Johnson N, Revenga C, Echeverria J: Managing water for people and nature. Science 200I, 292:107I-I072.

2. Somerville $C$, Briscoe J: Genetic engineering and water. Science 200I, 292:22I7.

3. Zhang JZ, Creelman RA, Zhu J-K: From laboratory to field. Using information from Arabidopsis to engineer salt, cold, and drought tolerance in crops. Plant Physiol 2004, 135:6I5-62।.

4. Saranga Y, Jiang CX, Wright RJ, Yakir D, Paterson AH: Genetic dissection of cotton physiological responses to arid conditions and their inter-relationships with productivity. Plant, Cell \& Environment 2004, 27:263-277.

5. Vinocur B, Altman A: Recent advances in engineering plant tolerance to abiotic stress: achievements and limitations. Current Opinion in Biotechnology 2005, 16:123-132.

6. Umezawa T, Fujita M, Fujita Y, Yamaguchi-Shinozaki K, Shinozaki K: Engineering drought tolerance in plants: discovering and tailoring genes to unlock the future. Current Opinion in Biotechnology 2006, 17:113-122

7. Catala R, Ouyang J, Abreu IA, Hu Y, Seo H, Zhang X, Chua N-H: The Arabidopsis E3 SUMO ligase SIZI regulates plant growth and drought responses. Plant Cell 2007, 19:2952-2966.

8. Fujita Y, Fujita M, Satoh R, Maruyama K, Parvez MM, Seki M, Hiratsu $\mathrm{K}$, Ohme-Takagi M, Shinozaki K, Yamaguchi-Shinozaki K: AREB I is a transcription activator of novel ABRE-Dependent ABA signaling that enhances drought stress tolerance in Arabidopsis. The Plant Cell 2005, I 7:3470-3488.

9. Weele CM van der, Spollen WG, Sharp RE, Baskin TI: Growth of Arabidopsis thaliana seedlings under water deficit studied by control of water potential in nutrient-agar media. J Exp Bot 2000, 5 I: I555-I562.

10. Verslues PE, Agarwal M, Katiyar-Agarwal S, Zhu J, Zhu J-K: Methods and concepts in quantifying resistance to drought, salt and freezing, abiotic stresses that affect plant water status. The Plant Journal 2006, 45:523-539.

II. Bhatnagar-Mathur P, Vadez V, Sharma K: Transgenic approaches for abiotic stress tolerance in plants: retrospect and prospects. Plant Cell Rep 2008, 27(3):4 I I-424.

12. Riga $P$, Vartanian N: Sequential expression of adaptive mechanisms is responsible for drought resistance in tobacco. Australian Journal of Plant Physiology 1999, 26:21 I-220.

13. Passioura JB: The perils of pot experiments. Functional Plant Biology 2006, 33: 1075-1079.

14. Jones HG: Monitoring plant and soil water status: established and novel methods revisited and their relevance to studies of drought tolerance. J Exp Bot 2007, 58: I 19-130.

15. Poulson M, Boeger M, Donahue R: Response of photosynthesis to high light and drought for Arabidopsis thaliana grown under a UV-B enhanced light regime. Photosynthesis Research 2006, 90:79-90.

16. Bhatnagar-Mathur P, Devi M, Reddy D, Lavanya M, Vadez V, Serraj R, Yamaguchi-Shinozaki K, Sharma K: Stress-inducible expression of AtDREBIA in transgenic peanut (Arachis hypogaea L.) increases transpiration efficiency under water-limiting conditions. Plant Cell Reports 2007, 26:207I-2082.

17. Mane SP, Vasquez-Robinet C, Sioson AA, Heath LS, Grene R: Early PLDa-mediated events in response to progressive drought stress in Arabidopsis: a transcriptome analysis. J Exp Bot 2007, 58:24I-252.

18. Karaba A, Dixit S, Greco R, Aharoni A, Trijatmiko KR, Marsch-Martinez N, Krishnan A, Nataraja KN, Udayakumar M, Pereira A: Improvement of water use efficiency in rice by expression of HARDY, an Arabidopsis drought and salt tolerance gene. Proceedings of the National Academy of Sciences 2007, 104:15270- 15275.

19. Qin F, Kakimoto M, Sakuma Y, Maruyama K, Osakabe Y, Tran L-SP, Shinozaki K, Yamaguchi-Shinozaki K: Regulation and functional analysis of ZmDREB2A in response to drought and heat stresses in Zea mays $L$. The Plant Journal 2007, 50:54-69.

20. Chen M, Wang Q-Y, Cheng X-G, Xu Z-S, Li L-C, Ye X-G, Xia L-Q, Ma Y-Z: GmDREB2, a soybean DRE-binding transcription factor, conferred drought and high-salt tolerance in transgenic plants. Biochemical and Biophysical Research Communications 2007, 353:299-305.

21. Chaves MM: Effects of water deficits on carbon assimilation. $J$ Exp Bot 1991, 42:1-16 [http://jxb.oxfordjournals.org/cgi/content/ abstract/42/I/I].

22. Tezara W, Mitchell VJ, Driscoll SD, Lawlor DW: Water stress inhibits plant photosynthesis by decreasing coupling factor and ATP. Nature 1999, 401:914-917.

23. Flexas J, Medrano H: Drought-inhibition of photosynthesis in C3 plants: stomatal and non-stomatal limitations revisited. Ann Bot 2002, 89:183-189.

24. Cornic G: Drought stress inhibits photosynthesis by decreasing stomatal aperture - not by affecting ATP synthesis. Trends in Plant Science 2000, 5:187-I88.

25. Oxborough K: Imaging of chlorophyll $a$ fluorescence: theoretical and practical aspects of an emerging technique for the monitoring of photosynthetic performance. J Exp Bot 2004, 55: $1195-1205$.

26. Baker NR: Chlorophyll fluorescence: a probe of photosynthesis in vivo. Annual Review of Plant Biology 2008, 59:89-1 I3.

27. Schreiber U, Vidaver W, Runeckles VC, Rosen P: Chlorophyll fluorescence assay for ozone injury in intact plants. Plant Physiol 1978, 61:80-84.

28. Conroy JP, Smillie RM, Kuppers M, Bevege DI, Barlow EW: Chlorophyll $a$ fluorescence and photosynthetic and growth responses of Pinus radiata to phosphorus deficiency, drought stress, and high $\mathrm{CO}_{2}$. Plant Physiol 1986, 81 1:423-429.

29. Lazár D: The polyphasic chlorophyll a fluorescence rise measured under high intensity of exciting light. Functional Plant Biology 2006, 33:9-30.

30. Oukarroum A, Strasser RJ: Phenotyping of dark and light adapted barley plants by the fast chlorophyll $a$ fluorescence rise OJIP. South African Journal of Botany 2004, 70:277-283.

31. Strauss A], Krüger GH], Strasser RJ, Heerden PDRV: Ranking of dark chilling tolerance in soybean genotypes probed by the chlorophyll a fluorescence transient O-J-I-P. Environmental and Experimental Botany 2006, 56:147-157. 
32. Oukarroum A, Madidi SE, Schansker G, Strasser RJ: Probing the responses of barley cultivars (Hordeum vulgare L.) by chlorophyll $a$ fluorescence OLKJIP under drought stress and rewatering. Environmental and Experimental Botany 2007, 60:438-446.

33. Omasa K, Shimazaki K-I, Aiga I, Larcher W, Onoe M: Image analysis of chlorophyll fluorescence transients for diagnosing the photosynthetic system of attached leaves. Plant Physiol 1987, 84:748-752.

34. Quilliam RS, Swarbrick PJ, Scholes JD, Rolfe SA: Imaging photosynthesis in wounded leaves of Arabidopsis thaliana. J Exp Bot 2006, 57:55-69.

35. Baker NR, Rosenqvist E: Applications of chlorophyll fluorescence can improve crop production strategies: an examination of future possibilities. J Exp Bot 2004, 55: I607-I62I.

36. Savitch L, Barker-Åstrom J, Ivanov A, Hurry V, Öquist G, Huner N, Gardeström P: Cold acclimation of Arabidopsis thaliana results in incomplete recovery of photosynthetic capacity, associated with an increased reduction of the chloroplast stroma. Planta 200I, 2 I 4:295-303.

37. Ehlert B, Hincha D: Chlorophyll fluorescence imaging accurately quantifies freezing damage and cold acclimation responses in Arabidopsis leaves. Plant Methods 2008, 4:12.

38. Muller-Moule P, Golan T, Niyogi KK: Ascorbate-deficient mutants of Arabidopsis grow in high light despite chronic photooxidative stress. Plant Physiol 2004, I 34: I I 63-I I 72.

39. Maxwell K, Johnson GN: Chlorophyll fluorescence - a practical guide. J Exp Bot 2000, 5 I:659-668.

40. Lawlor DW, Cornic G: Photosynthetic carbon assimilation and associated metabolism in relation to water deficits in higher plants. Plant, Cell and Environment 2002, 25:275-294.

41. Kramer D, Johnson G, Kiirats O, Edwards G: New fluorescence parameters for the determination of $\mathbf{Q}_{a}$ redox state and excitation energy fluxes. Photosynthesis Research 2004, 79:209-218.

42. Rossel JB, Walter PB, Hendrickson L, Chow WS, Poole A, Mullineaux PM, Pogson BJ: A mutation affecting ASCORBATE PEROXIDASE 2 gene expression reveals a link between responses to high light and drought tolerance. Plant, Cell and Environment 2006, 29:269-28I.

43. Mustilli A-C, Merlot S, Vavasseur A, Fenzi F, Giraudat J: Arabidopsis OSTI protein kinase mediates the regulation of stomatal aperture by abscisic acid and acts upstream of reactive oxygen species production. Plant Cell 2002, I 4:3089-3099.

44. Sakamoto W, Tamura T, Hanba-Tomita Y, Murata M: The VARI locus of Arabidopsis encodes a chloroplastic FtsH and is responsible for leaf variegation in the mutant alleles. Genes Cells 2002, 7:769-780.

45. Chen $M$, Jensen $M$, Rodermel $S$ : The yellow variegated mutant of Arabidopsis is plastid autonomous and delayed in chloroplast biogenesis. J Hered 1999, 90:207-2।4.

46. Mittler R, Kim Y, Song L, Coutu J, Coutu A, Ciftci-Yilmaz S, Lee H, Stevenson B, Zhu J-K: Gain- and loss-of-function mutations in ZATI 0 enhance the tolerance of plants to abiotic stress. FEBS letters 2006, 580:6537-6542.

47. Sakamoto H, Maruyama K, Sakuma Y, Meshi T, Iwabuchi M, Shinozaki K, Yamaguchi-Shinozaki K: Arabidopsis Cys2/His2-type zinc-finger proteins function as transcription repressors under drought, cold, and high-salinity stress conditions. Plant Physiol 2004, I 36:2734-2746.

48. Rossel JB, Wilson PB, Hussain D, Woo NS, Gordon MJ, Mewett OP, Howell KA, Whelan J, Kazan K, Pogson B]: Systemic and intracelIular responses to photooxidative stress in Arabidopsis. Plant Cell 2007, I 9:409I-4II0.

49. Gray GR, Hope BJ, Qin X, Taylor BG, Whitehead CL: The characterization of photoinhibition and recovery during cold acclimation in Arabidopsis thaliana using chlorophyll fluorescence imaging. Physiologia Plantarum 2003, I I 9:365-375.

50. Rizza F, Pagani D, Stanca AM, Cattivelli L: Use of chlorophyll fluorescence to evaluate the cold acclimation and freezing tolerance of winter and spring oats. Plant Breeding 200 I, I 20:389-396.

51. Giardi MT, Cona A, Geiken B, Kuèera T, Masojídek J, Mattoo AK: Long-term drought stress induces structural and functional reorganization of photosystem II. Planta 1996, I99: I I8-I25.

52. Hura T, Grzesiak S, Hura K, Thiemt E, Tokarz K, Wedzony M: Physiological and biochemical tools useful in drought-tolerance detection in genotypes of winter triticale: accumulation of ferulic acid correlates with drought tolerance. Annals of Botany 2007, 100:767-775.

53. Flexas J, Bota J, Escalona JM, Sampol B, Medrano H: Effects of drought on photosynthesis in grapevines under field conditions: an evaluation of stomatal and mesophyll limitations. Functional Plant Biology 2002, 29:46I-47I.

54. Flexas J, Escalona JM, Medrano H: Down-regulation of photosynthesis by drought under field conditions in grapevine leaves. Functional Plant Biology 1998, 25:893-900.

55. Rivero RM, Kojima M, Gepstein A, Sakakibara H, Mittler R, Gepstein $S$, Blumwald E: Delayed leaf senescence induces extreme drought tolerance in a flowering plant. Proceedings of the National Academy of Sciences 2007, I 04: I 9631-19636.

56. Öquist G, Chow WS, Anderson JM: Photoinhibition of photosynthesis represents a mechanism for the long-term regulation of photosystem II. Planta 1992, 186:450-460.

57. Cornic G, Gouallec JL, Briantais JM, Hodges M: Effect of dehydration and high light on photosynthesis of two C3 plants (Phaseolus vulgaris $\mathbf{L}$. and Elatostema repens (Lour.) Hall f.). Planta 1989, I 77:84-90.

58. Hoagland DR, Arnon DA: The water-culture method of growing plants without soil. California Agricultural Experiment Station Circular 1938, 347:1-32
Publish with Bio Med Central and every scientist can read your work free of charge

"BioMed Central will be the most significant development for disseminating the results of biomedical research in our lifetime. "

Sir Paul Nurse, Cancer Research UK

Your research papers will be:

- available free of charge to the entire biomedical community

- peer reviewed and published immediately upon acceptance

- cited in PubMed and archived on PubMed Central

- yours - you keep the copyright

Submit your manuscript here:

http://www.biomedcentral.com/info/publishing_adv.asp
BioMedcentral 